\title{
GLYCEMIC EFFECTS OF SOLANINE IN RATS*
}

\author{
TETSUO SATOH \\ Department of Pharmacology and Toxicology, The Institute of Food Microbiology, \\ Chiba University, Narashino, Chiba
}

Received for publication June 14, 1967

It has been widely recognized that solanine (Fig. 1) is contained in Solanum species, especially in fresh potato sprouts as a toxic alkaloid.

There have been reports concerning solanine, namely, Kline et al. (1) reported that potato sprouts were shown to be toxic to pregnant rats when fed at a level of $10 \%$ of the diet. Solanine and solanidine, aglycon of solanine, inhibit human plasma cholinesterase in vitro $(2,3)$. No other pharmacological and biochemical studies on toxicities of solanine have been published.

The present investigation was undertaken to determine the alteration of blood sugar level of rat treated with solanine.

Hyperglycemia has been reported as one feature of poisoning by some toxic substances, i.e., guthion (4), paracetamol (5), parathion (6) and amphetamine (7). It seemed possible, therefore, that changes of disturbance of carbohydrate metabolism.

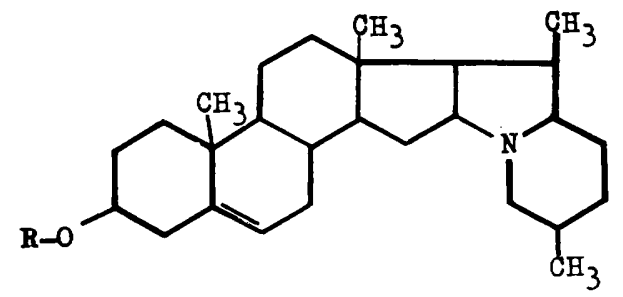

FIG. 1. Chemical structures of solanine and solanidine.

$\mathrm{R}=\mathrm{C}_{6} \mathrm{H}_{0}^{\mathrm{T}} \mathrm{O}_{4}-\mathrm{O}-\mathrm{C}_{6} \mathrm{H}_{10} \mathrm{O}_{4}-\mathrm{O}-\mathrm{C}_{6} \mathrm{H}_{11} \mathrm{O}_{4}$ : solanine

glucose galactose rhamnose

$\mathrm{R}=\mathrm{H}$ : solanidine

\section{MATERIALS AND METHODS}

Adult male and female Wistar rats weighing 150-250 g were employed in this study. Solanine** was dissolved in dilute hydrochloric acid (approx. $0.005 \mathrm{~N}$ ) immediately before use and injected i.p.

All experiments included control animals which received equal volume doses $(0.1$ $\mathrm{ml} / 100 \mathrm{~g}$ body weight) of the dilute hydrochloric acid. Adrenergic blocking agents were injected an appropriate time prior to administration of solanine. The procedure of with-

传藤 哲男

* The essentials of this work were successively reported at the 40th Annual Meeting of the Japanese Pharmacological Society at Nagoya (8) and the 24th Annual Meeting of the Pharmaceutical Society of Japan at Kyoto (9).

** Solanine obtained from Merck, Darmstadt, Germany. 
drawing of blood from small incision in rat tail and measuring of blood sugar level have been described in previous paper (10). Estimation of color that developed when $0.5 \mathrm{ml}$ aliquot of deproteinized sample was added to reagent could be measured at $610 \mathrm{~m} \mu$ on Bausch Lamb Spectronic 20 colorimeter. For glycogen measurement animals were sacrificed by decapitation 1 hour after administration of solanine i.p. in a dose of $5 \mathrm{mg} / \mathrm{kg}$, and tissues were removed as quickly as possible and duplicate samples of 100-200 $\mathrm{mg}$ of liver, heart and diaphragm frozen between two blocks of dry ice were digested by boiling with $30 \%$ potassium hydroxide, washed and precipitated twice with 95\% ethanol overnight.

The precipitate was resuspended in an appropriate volume of water and color developed was measured as determination of blood sugar using anthrone reagent (11).

Bilateral adrenalecotmies were performed under pentobarbital anesthesia and the animals were maintained on $1 \%$ sodium chloride solution as drinking water and a commmercial diet ad libitum. The operated rats were used in experiments 5-7 days after surgery, moreover, the completeness of the removal of the glands was verified by visual observation at autopsy.

Results ware analyzed by Student's test and the criterion used for significance was a $\mathrm{P}$ value of less than or equal to 0.05 .

\section{RESULTS}

Effects of solanine on blood sugar levels in intact rats

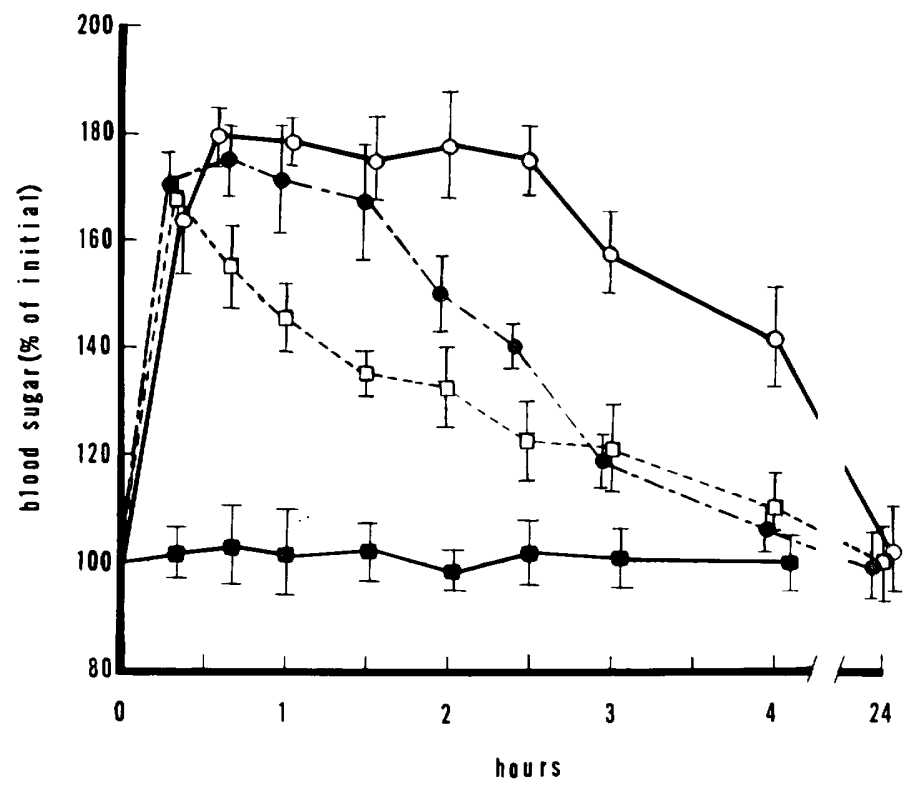

FIG. 2. Effects of various doses of solanine on blood sugar levels of intact rats. The responses of solanine of three doses were investigated over 4 hours after injections. Doses of solanine : - - None ; $-\square-, 5 \mathrm{mg} / \mathrm{kg} ;--_{-}, 15 \mathrm{mg} / \mathrm{kg} ;-\bigcirc_{-}, 30 \mathrm{mg} / \mathrm{kg}$.

Throughout the figures in this paper, following expressions hold : Each point indicated mean value of at least 5 experiments, and the vertical lines represented standard error of the mean. Solanine was injected i.p. Blood sugar levels were shown as per cent changes of initial levels. 
A study of the effect of solanine at various time intervals after injection in male rats is summarized in Fig. 2. The changes in blood sugar level at appropriate time intervals are shown as percentages of initial levels throughout the present paper except for glucose tolerance tests, and the curves represent the mean value for each group with standard error of the mean.

Blood sugar level of the rat after solanine markedly increased at 30 minutes later and gradually restored and, 24 hours later, recovery of blood sugar was completely accomplished to initial level. This increase in blood sugar was proportional to doses and, in lower doses, recovery was more rapidly compared with those of relatively high doses. Sex difference of solanine induced hyperglycemia

In hyperglycemic effect of solanine there was considerable sex difference in the duration and maximum of response to solanine (30 mg/kg i.p.). The hyperglycemic action was much longer in female rats than in males (Fig. 3a), however, reverse phenomena were obtained in female and male rats after starvation for 24 hours (Fig. 3b).



Fig. 3. Sex difference in solanine induced hyperglycemia of rats. (a) Rats were fed ordinary diet throughout experiments. (b) Rats were starved for 24 hours before solanine administration. Sex of rats employed are indicated as follows. Control : - - -, male ; $-\square-$, female ; treated : - - male ; - - , female. Solanine injected : 30 $\mathrm{mg} / \mathrm{kg}$ i.p.

Since these results seemed to be complicated including hormonal effects and other factors, detailed discussion of this subject will be reported in successive paper.

Blockade of solanine induced hyperglycemia by adrenergic blocking agents in intact rats

All blocking agents were used as salt and their doses were expressed in terms of the base. It appeared that the early increase in blood sugar might be causally related to sympathomimetic effect of solanine.

To determine this effect, following four adrenergic blocking agents were used: dihydroergotamine (DHE), $3.5 \mathrm{mg} / \mathrm{kg}$ s.c.; propranolol (PPL), $4 \mathrm{mg} / \mathrm{kg}$ i.p.; dichloroisoproterenol (DCI), $10 \mathrm{mg} / \mathrm{kg}$ s.c. and chlorpromazine (GPZ) which was used here as an alpha blocker, $5 \mathrm{mg} / \mathrm{kg}$ s.c.

Except for CPZ which produced an increase in blood sugar, pretreatment with these blocking agents, DHE, PPL and DCI at appropriate time to rat suppressed, to some extent, increase in blood sugar caused by solanine (Fig. 4a-c). No effect due to GPZ on depression to hyperglycemia elicited by solanine seemed to be masked by hyperglycemic action of CPZ itself (Fig. 4d). 


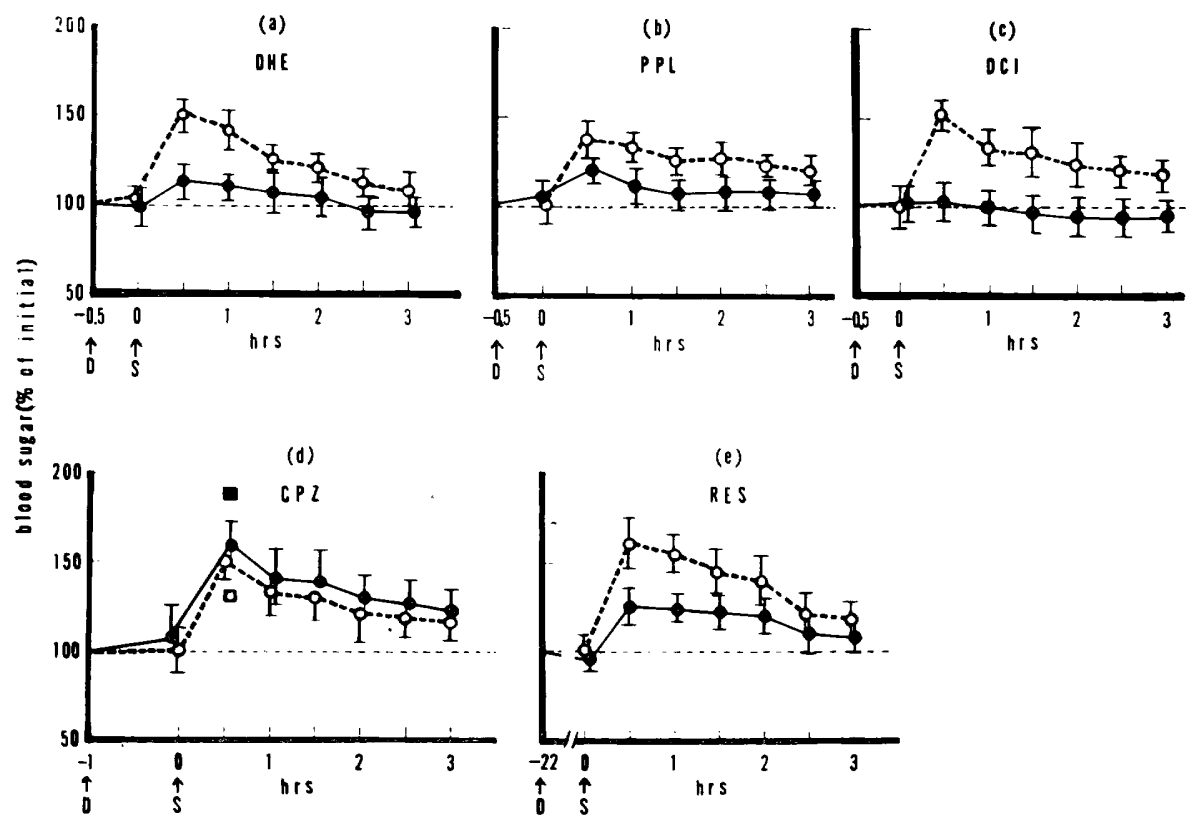

Fig. 4. Effects of drug pretreatment on the blood sugar levels of solanine treated rats. Drugs were pretreated at appropriate time (D point) before solanine (S point on the figures). The pretreatment doses were : $\mathrm{DHE}=$ dihydroergotamine, $3.5 \mathrm{mg} / \mathrm{kg}$ s.c. ; PPL= propranolol, $4.0 \mathrm{mg} / \mathrm{kg}$ i.p. ; DCI $=$ dichloroisoproterenol, $10 \mathrm{mg} / \mathrm{kg}$ s.c. ; $\mathrm{CPZ}=$ chlorpromazine, $5 \mathrm{mg} / \mathrm{kg}$ s.c. ; RES $=$ reserpine, $5 \mathrm{mg} / \mathrm{kg}$ s.c. $-\mathrm{O}^{-}$, solanine alone ; - -, drug pretreatment. In Fig. 4d, $\square$ and $\square$ indicated blood sugar levels of rats treated with $\mathrm{CPZ}+$ solanine and CPZ alone respectively. - indicated true CPZ effect on solanine hyperglycemia, obtained by subtracting the value for GPZ alone from GPZ+ solanine.

Furthermore, pretreatment with reserpine in a dose of $5 \mathrm{mg} / \mathrm{kg}$ s.c. in rats 22 hours prior to administration of solanine confirmed that this hyperglycemia was caused through epinephrine (Fig. 4e).

In these results there was no difference of effect between alpha and beta agents. As reported by many investigators $(4,5,12,15)$, it is likely that blood sugar level is mediated by alpha as well as beta receptors.

\section{Effects of solanine on blood sugar levels in adrenalectomized rats}

Since an increase in blood sugar after administration of solanine in intact rats might be a result of stimulation to adrenals, adrenalectomized rats were employed in the experiments of solanine induced hyperglycemia.

As shown in Fig. 5a no increase in blood sugar was observed after solanine in adrenalectomized rats, moreover, significant depletion of blood sugar occurred to approximately $40 \%$ of initial level at 2 to 4 hours after administration. Treatment with relatively high doses of solanine to adrenalectomized rats caused death at 3 hours after treatment (indicated by cross). 
In starved adrenalectomized rats for 24 hours, less reduction in blood sugar level was observed, comparing with those of fed ones, moreover, no animals subjected to injection of solanine caused to death (Fig. 5b). These results revealed that starvation was closely related to glycemic effect of solanine and this fact could be also referred to the results illustrated in Figs. 2a and b.

Changes of glucose tolerance curves in rats treated with solanine

In addition to findings of sympathomimetic effect of solanine, glucose tolerance test was carried out to determine changes of peripheral utilization of glucose after solanine. As illustrated in Fig. 6a, the resulting hyperglycemia was more pronounced and glucose tolerance curve was more protracted than normally.

It appeared to reduction of glucose tolerance of intact rats treated with solanine, that is, peripheral utilization of glucose was impaired by solanine. Despite of admini-

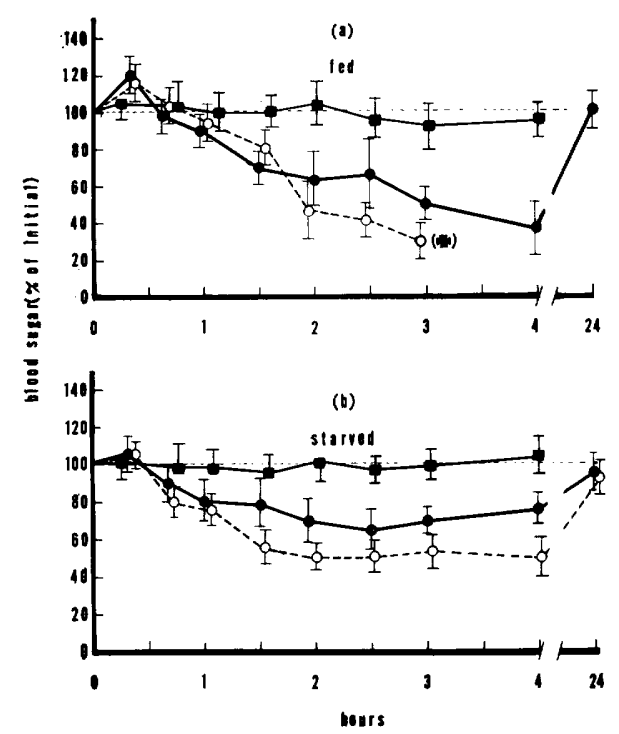

Fig. 5. Effects of adrenalectomy on glycemic action of solanine. Adrenalectomy was carried out 5-7 days before the experiments. (a) : rats were fed ordinary diet throughout experiments. (b) : rats were starved for 24 hours before solanine administration. Doses of solanine : - - , none ; - $-5 \mathrm{mg} / \mathrm{kg} ;-\mathrm{O}^{-}, 15 \mathrm{mg} / \mathrm{kg}$. All fed rats treated with solanine of relatively high dose died at 3 hours after administration (indicated by cross).

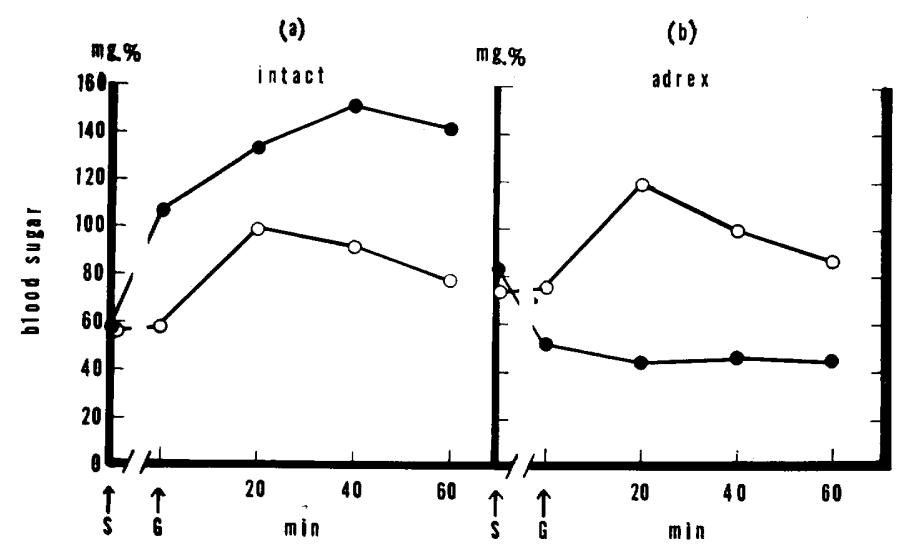

FIG. 6. Effect of solanine on glucose tolerance test in intact and adrenalectomized (adrex) rats. Two points, S and $\mathrm{G}$ on the figures represented administration of solanine $(5 \mathrm{mg} / \mathrm{kg}$ i.p.) 1 hour prior to glucose load $(2 \mathrm{~g} / \mathrm{kg}$ i.p.) in $50 \%$ glucose solution respectively. Blood samples were withdrawn at 20,40 and 60 minutes after glucose administration. Control rats received $0.9 \%$ saline instead of solanine.

-, taeated ; - - -, control. 
stration of glucose, whereas, no elevation of blood sugar was observed in adrenalectomized rats which were pretreated with solanine (Fig. 6b).

This fact could be responsible for hypoglycemic effect of solanine in adrenalectomized rats described elsewhere in this paper. As detailed mechanism is unknown, studies on these phenomena are under investigation.

Effects of solanine on tissue glycogen levels in intact rats

In relation to hyperglycemia induced by solanine, changes of tissue glycogen levels were examined. Groups of 5 male rats were injected with solanine in a dose of $5 \mathrm{mg} / \mathrm{kg}$ i.p. and, 1 hour later, hepatic glycogen decreased from control of $210.6 \pm 21.5$ to $173 \pm$ $14.5 \mathrm{mg} / 100 \mathrm{~g}$ tissue $(\mathrm{P}<0.05)$, while those of diaphragm and heart remained approximately unchanged for 1 hour showing only a slight decrease from $14.2 \pm 1.60$ to $11.4 \pm$ 2.26 in heart and $14.1 \pm 2.02$ to $10.8 \pm 1.08 \mathrm{mg} / 100 \mathrm{~g}$ tissue in diaphragm respectively. These values were not significant statistically.

\section{DISCUSSION}

The present study has shown that solanine causes an increase in blood sugar level in intact rats, and hypoglycemia in adrenalectomized rats. The mechanisms responsible for two effects have been investigated.

For hyperglycemia in intact rats appears to be mediated through stimulation of adrenals. Thus pretreatment with either three adrenergic blockers, DHE, DCI and PPL, or reserpine lead to prevent the increase in blood sugar of rat treated with solanine.

With regard to effects of adrenergic blocking agents on carbohydrate metabolism and lipolysis which closely associated with glycolysis, several reports have been available. The observation by Estler and Ammon (14) revealed that PPL as well as DCI has direct inhibitory effects on phosphorylase activity. Goodman (15) has reported that ergotamine prevents epinephrine-induced free fatty acid release in rat. Dibenamine was reported to prevent free fatty acid mobilization in the dog (16).

A recent report by Jori and Carrara (13) has indicated that beta adrenergic blockers also act to prevent increase in blood sugar caused by epinephrine or CPZ on which reported by other investigators (17-22).

Different results obtained from starved rats from fed ones suggested that solanine induced hyperglycemia might be related with liver glycogen level. The results presented above suggest that other factors may contribute to hyperglycemia. The decreased glycogen level in liver, but not in heart and diaphragm, that occurred 1 hour after solanine might be accounted for in part on the increase in blood sugar due to activation of glycogenolysis.

On the other hand, sex difference in solanine elicited hyperglycemia is also of interest to assume that sex hormones might be related to changes of carbohydrate metabolism in treatment with solanine. Since these endocrinological phenomena are much complicated, further studies are in progress in this laboratory.

Loading with glucose results in a more pronounced hyperglycemia in intact rats treated with solanine than in controls. These results support the view that solanine may, 
at least in part, act as a hyperglycemic agent by impairing utilization of glucose.

Finally, these conclusions do not exclude other explanations such as effect of solanine on enzymes relevant to carbohydrate metabolism or an effect on cell permeability to glucose. These glycemic effects of solanine were not observed in treatment routes other than i.p. (not presented here).

\section{SUMMARY}

The alkaloid, solanine, has been found to increase blood sugar level in intact rats. This hyperglycemia was, to a certain extent, prevented by pretreatment with either adrenergic blockers or reserpine, not with chlorpromazine. Inhibition of peripheral utilization of glucose was also observed in glucose tolerance tests. On the other hand, hypoglycemia was found in adrenalectomized rats. Furthermore, there was considerable sex difference in solanine induced hyperglycemia. These phenomena were found in rats only when administered i.p., not by other administration routes.

Acknowledgement: The author wishes to express his deep gratitude to Dr. Yasumi Ogura in this laboratory for his continued criticism and advice.

\section{REFERENCES}

1) Kline, B.E., Elbe, H.v., Dahle, N.A. and Kupchan, S.M.: Proc. Soc. exp. Biol. Med. 107, 807 (1961)

2) Orgell, W.E., Vaidya, K.A. and Dahn, M.J.: Science, N.Y. 128, 1136 (1958)

3) Menn, J.J., McBain, J.B. and Dennis, M.J.: Nature Lond. 16, 697 (1964)

4) Murphy, S.D. And Porter, S.: Biochem. Pharmac. 15, 1665 (1966)

5) Boyd, E.M. and Bereczky, G.M.: Br. J. Pharmac. Chemother. 26, 606 (1966)

6) Weiss, L.R., Bryant, J. and Fitzbugh, O.G.: Toxic. appl. Pharmac. 6, 363 (1964)

7) Moore, K.E., Sawdy, L.C. And Shaul, S.R.: Biochem. Pharmac. 14, 197 (1965)

8) Ogura, Y. And SAToh, T.: Folia pharmacol. japon. 63, 39\$ (1967)

9) SAтон, T.: Abstracts of Papers, 24th Annual Meeting of the Pharmaceutical Society of Japan, p. 330, Kyoto, April (1967)

10) Satoh, T. and Iwamoto, T.: Biochem. Pharmac. 15, 323 (1966)

11) Roe, J.E.: J. biol. Chem. 212, 197 (1965)

12) Kvan, D.C., Riggilo, D.A. and Lish, P.M.: J. Pharmac. exp. Ther. 149, 183 (1965)

13) Jori, A. and Cararra, M.C.: J. Pharm. Pharmac. 18, 623 (1966)

14) Estler, C.J. And Ammon, H.P.T.: Biochem. Pharmac. 15, 2031 (1966)

15) Goodman, H.M. and Knobil, E.: Proc. Soc. exp. Biol. Med. 102, 493 (1959)

16) Haver, R.J. And Goldfrien, A.: J. Lipid Res. 1, 102 (1959)

17) Bonaccorsi, A., Garrattini, S. and Jori, A.: Br. J. Pharmac. Chemother. 23, 93 (1964)

18) Ryall, R.W.: Ibid. 11, 339 (1956)

19) Jori, A., Bernardi, D. and Garratini, S.: Int. J. Neuropharmac. 3, 553 (1964)

20) Jori, A. And Bianchetti, A.: Ibid. 5, 435 (1966)

21) Norman, D. and Hiestand, W.A.: Proc. Soc. exp. Biol. Med. 90, 89 (1955)

22) Simoes, M.S. and Oswald, W.: Metabolism 4, 333 (1955) 